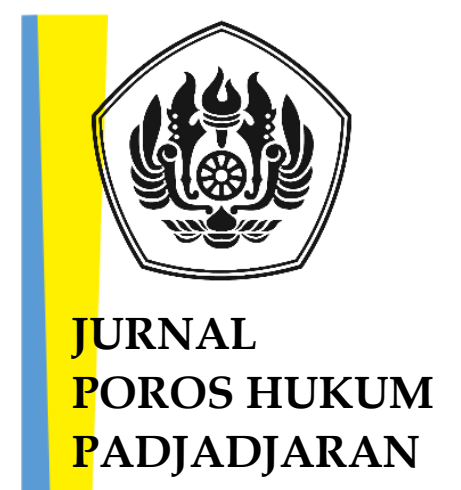

P-ISSN: 2715-7202

E-ISSN: 2715-9418

Artikel diterbitkan:

29 Mei 2020

DOI:

https://doi.org/10.23920/jphp .v1i2.292

Halaman Publikasi: http://jurnal.fh.unpad.ac.id/i ndex.php/JPHP/issue/archive

Diterbitkan oleh:

Fakultas Hukum

Universitas Padjadjaran

\section{IMPLIKASI PERATURAN PEMERINTAH NOMOR 54 TAHUN 2017 TENTANG BUMD TERHADAP PENJAMINAN ASET BUMD KEPADA BANK}

\section{IMPLICATIONS OF GOVERNMENT REGULATION NUMBER 54 YEAR 2017 TO THE GUARANTEE OF REGIONAL OWNED ENTERPRISES ASSETS}

\section{Mentari Octovia ${ }^{a}$}

\begin{abstract}
ABSTRAK
Artikel ini menganalisis Peraturan Pemerintah Nomor 54 Tahun 2017 tentang BUMD khususnya Pasal 95 yang mengatur bahwa dalam rangka pengembangan usahanya BUMD diperbolehkan untuk menjaminkan asetnya yang berasal dari hasil usaha, tetapi tidak mengatur mengenai kebolehan BUMD untuk menjaminkan asetnya apabila BUMD masih membukukan rugi dan belum memiliki hasil usaha. Tujuan artikel ini adalah untuk memberikan kejelasan mengenai kebolehan penjaminan aset BUMD kepada bank dan menegaskan keterpisahannya dengan aset daerah. Metode penelitian yang digunakan bersifat deskriptif analitis dengan pendekatan yuridis normatif. Temuan ini membuktikan bahwa Peraturan Pemerintah Nomor 54 Tahun 2017 tentang BUMD secara implisit turut mengakui pada Pasal 3 bahwa penjaminan aset BUMD dengan nilai lebih dari 50\% kekayaan bersih BUMD dapat dilakukan selama mendapat persetujuan kepala daerah atau perwakilannya. Ketentuan ini mengimplikasikan tidak adanya pembedaan terhadap aset mana yang dapat dijaminkan, menegaskan perbedaannya dengan aset daerah dan juga selaras dengan ketentuan mengenai penjaminan aset Perseroan Terbatas dalam perundang-undangan.
\end{abstract}

Kata kunci: BUMD; peraturan pemerintah; penjaminan asset; pinjaman bank

Program Studi Magister Ilmu Hukum, Fakultas Hukum Universitas Padjadjaran, Jl. Banda No. 21 Bandung, email: mentari.octovia@gmail.com. 


\begin{abstract}
This article analyzes the Government Regulation Number 54 Year 2017 concerning Regional OwnedEnterprise (ROEs), particularly Article 95 which regulates that ROEs are allowed to obtain bank loan and guarantee their assets originating from business revenues in the context of business development, but does not regulate its ability to guarantee their assets if ROEs still prosted a loss and do not earn profits yet. This article aims to provide clarity regarding ROEs ability in guaranteeing their aseets to banks and emphasize its separation from regional assets. The research method used is decriptive analytical with normative juridical approach. The finding proves that the Government Regulation Number 54 Year 2017 implicitly acknowledge in Article 3 that the guarantee of ROEs asset with a value of more than $50 \%$ of ROEs net worth can be carried out as long as it is approved by the regional head or his representative. Therefore, it implies that there is no distinction between which assets can be guaranteed, confirms its diference with the regional assets, and it is also in line with the regulations regarding guarantee of limited liability company's assets.
\end{abstract}

Keywords: regional owned enterprise; government regulation; assets guarantee; bank loan.

\title{
PENDAHULUAN
}

Opsi pendanaan melalui pinjaman perbankan merupakan salah satu cara pembiayaan yang lazim digunakan oleh Badan Usaha Milik Daerah (“BUMD”), khususnya BUMD yang berbentuk Perseroan Terbatas (disebut Perseroda). Hal ini merupakan salah satu bentuk kemandirian yang dapat ditunjukkan BUMD agar mandiri dalam mencari permodalan untuk pengembangan usaha dan investasi dengan tidak mengandalkan permodalan melalui penyertaan Daerah. Namun demikian, sesuai asas collateral dalam pemberian pinjaman, perbankan akan mempersyaratkan jaminan sebelum mencairkan kredit kepada BUMD, yang digunakan untuk berjaga-jaga seandainya debitur tidak dapat mengembalikan pinjamannya. ${ }^{1}$

Peraturan Pemerintah Nomor 54 Tahun 2017 tentang BUMD (“PP BUMD”) yang diterbitkan sebagai amanat dari Undang-Undang Nomor 23 Tahun 2014 tentang Pemerintah Daerah (“UU PEMDA”) sebagai pengaturan teknis perihal penyelenggaraan dan pengelolaan BUMD mengatur terkait tindakan pinjaman bank dan aset BUMD sebagai berikut:

a. Pasal 19 ayat (3) juncto Pasal 26 PP BUMD: Pinjaman disebutkan sebagai salah satu sumber modal BUMD. BUMD dapat melakukan pinjaman sesuai dengan kelaziman

1 Sentosa Sembiring (2007). Arti Penting Jaminan dalam Pemberian Kredit dalam Transaksi Bisnis Perbankan. Gloria Juris, 7(1), hlm. 25-26. 
dalam dunia usaha. Ketentuan mengenai penerimaan pinjaman dilaksanakan sesuai dengan ketentuan peraturan perundang-undangan.

b. Pasal 95 ayat (1) dan (2) PP BUMD: Pinjaman dapat dilakukan BUMD kepada lembaga keuangan, pemerintah, dan sumber dana lainnya dalam negeri untuk pengembangan usaha dan investasi. Dalam hal pinjaman dimaksud mempersyaratkan jaminan, maka aset BUMD yang berasal dari hasil usaha BUMD dapat dijadikan jaminan untuk mendapatkan pinjaman.

Ketentuan Pasal 95 ayat (2) PP BUMD memberikan implikasi bahwa penjaminan aset BUMD dalam rangka pinjaman untuk pengembangan usaha dan investasi dapat dilakukan setelah BUMD memiliki hasil usaha. Ketentuan ini kontradiktif dengan semangat BUMD yang sedang menempuh upaya kemandirian permodalan melalui opsi pinjaman dari bank. Disamping itu ketentuan ini tidak menjawab mengenai kebolehan penjaminan untuk aset BUMD yang berasal dari pendapatan diluar hasil usaha. Sebagai konsekuensinya, maka semakin sulit untuk menetapkan aset mana yang boleh dijaminkan kepada bank untuk memperoleh pinjaman.

Pada praktiknya, BUMD berbentuk Perseroda menjaminkan asetnya dalam rangka memperoleh kredit bank meski belum memiliki hasil usaha. Kredit bank tersebut diperlukan untuk operasional perusahaan, seperti pada PT Bandarudara Internasional Jawa Barat untuk keperluan pembangunan bandara dan PT Tirta Gemah Ripah untuk pembangunan dan investasi Pembangkit Listrik Tenaga Air (Minihidro). Aset yang dijaminkan BUMD berbentuk Perseroda tersebut tidak berasal dari hasil usaha, melainkan dari penyertaan modal daerah maupun aset yang dibeli dari hasil pinjaman bank itu sendiri. ${ }^{2}$

Berdasarkan latar belakang masalah di atas, maka identifikasi permasalahan yang dapat dirumuskan yaitu kebolehan BUMD Perseroda untuk menjaminkan asetnya yang berasal dari diluar hasil usaha kepada bank. Tujuan penelitian ini diantaranya untuk memberikan kejelasan terkait status kepemilikan aset BUMD Perseroda dan penjaminannya berdasarkan perspektif hukum perusahaan, hukum BUMD, dan hukum keuangan daerah.

\footnotetext{
2 Hal ini dikarenakan kedua BUMD tersebut masih membukukan rugi.
} 


\section{METODE PENELITIAN}

Metode penelitian yang digunakan adalah metode pendekatan juridis normatif. ${ }^{3}$ Penulisan penelitian ini menggunakan metode deskriptis analitis, mengidentifikasi pengaturan-pengaturan terkait penjaminan aset BUMD yang kemudian dianalisis menggunakan data sekunder maupun data primer dengan bahan hukum primer, bahan hukum sekunder dan bahan hukum tersier, termasuk peraturan perundang-undangan yang berlaku. ${ }^{4}$

\section{PEMBAHASAN}

Subyek hukum ialah segala sesuatu yang pada dasarnya memiliki hak dan kewajiban dalam lalu lintas hukum, yaitu manusia (natuurlijke persoon) dan badan hukum (rechtpersoon). Badan usaha dikatakan berbadan hukum apabila memenuhi syarat-syarat sebagai badan hukum, antara lain: adanya kekayaan yang terpisah antara badan hukum dengan organ badan hukum; adanya tujuan tertentu yang terlepas dari tujuan organ badan hukum; adanya kepentingan tertentu yang terlepas dari kepentingan organ badan hukum; dan adanya organisasi yang teratur dengan pengurus yang mewakili badan hukum dalam bertindak. ${ }^{5}$ Pada saat ini dikenal adanya dua jenis badan hukum, yakni: badan hukum publik dan badan hukum perdata:

a. Badan hukum publik (Personne morale): yang mempunyai tugas dan kewenangan mengeluarkan kebijakan publik, baik yang mengikat umum (misalnya UU Perpajakan) atau tidak mengikat umum (misalnya UU APBN);

b. Badan hukum privat (Personne juridique): yang tidak mempunyai tugas dan kewenangan mengeluarkan kebijakan publik yang bersifat mengikat masyarakat umum. Hak dan kewajiban badan hukum privat lahir dari suatu hubungan hukum perjanjian atau kontrak antara dua subyek hukum atau lebih. ${ }^{6}$

3 Soerjono Soekanto. (1986). Pengantar Penelitian Hukum. Jakarta: UI Press, hlm. 51.

4 Sumadi Suryabrata. (2010). Metodologi Penelitian. Jakarta: Rajawali Pers, hlm. 76.

5 Tuti Rastuti. (2015). Seluk Beluk Perusahaan dan Hukum Perusahaan. Jakarta: PT Refika Aditama. p. 37.

6 Yuli Indrawati. (2014). In Memoriam Prof. Dr. Arifin P. Soeriaatmadja: Aktualisasi Hukum Keuangan Publik, Bandung: Mujahid Press. hlm. 11. 
Diterbitkannya UU PEMDA dan PP BUMD menetapkan klasifikasi terhadap BUMD, yaitu Perusahaan Umum Daerah (Perumda) dan Perusahaan Perseroan Daerah (Perseroda). Perumda adalah BUMD yang seluruh modalnya dimiliki oleh satu Daerah dan tidak terbagi atas saham,7 sedangkan Perseroda adalah BUMD yang berbentuk perseroan terbatas yang modalnya terbagi dalam saham yang seluruhnya atau paling sedikit $51 \%$ sahamnya dimiliki oleh satu Daerah. ${ }^{8}$ Salah satu perbedaan dari Perumda dan Perseroda adalah bentuk badan hukumnya, yang mana pada BUMD berbentuk Perseroda adalah bentuk badan hukumnya sebagai perseroan terbatas ("PT"). PT (Limited Liability Company, Naamlooze Vennootschap) merupakan badan hukum yang didirikan berdasarkan perjanjian untuk melakukan kegiatan usaha dengan modal dasar yang seluruhnya terbagi dalam saham, serta memenuhi persyaratan yang ditentukan dalam undang-undang dan peraturan pelaksananya.

\section{Status Kepemilikan Kekayaan BUMD Perseroda}

Bagi BUMD yang berbentuk PT dan modalnya terbagi atas saham (BUMD Perseroda), maka penyertaan modal Daerah pada Perseroda menjadi saham-saham di Perseroda. Ketentuan ini selaras dengan ketentuan Pasal 34 Undang-Undang Nomor 40 Tahun 2007 tentang Perseroan Terbatas (“UU Perseroan Terbatas”) yang mengatur bahwa penyetoran modal yang dilakukan dalam bentuk uang dan/atau dalam bentuk lainnya kepada PT menjadi penyetoran atas modal saham. Penyertaan modal Daerah pada BUMD yang berasal dari APBD ini selanjutnya disebut sebagai kekayaan daerah yang dipisahkan. ${ }^{9}$

Dalam BUMD Perseroda, maka secara konkrit, saham-saham yang telah ditempatkan dan disetor Pemerintah Daerah pada BUMD merupakan bentuk kekayaan daerah yang dipisahkan dalam BUMD Perseroda. Sesuai dengan Pasal 2 Peraturan Pemerintah Nomor 12 Tahun 2019 tentang Pengelolaan Keuangan Daerah, kekayaan daerah yang dipisahkan disebutkan termasuk ke dalam lingkup keuangan daerah. Dengan adanya kekayaan daerah yang dipisahkan yang termasuk lingkup keuangan daerah dalam BUMD maka menyebabkan ambiguitas tentang hukum kekayaan BUMD itu sendiri. Status uang badan

\footnotetext{
7 Pasal 334 ayat (1) UU PEMDA.

8 Pasal 339 ayat (1) UU PEMDA.

9 Pasal 1 angka (6) PP BUMD.
} 
hukum sangat erat kaitannya dengan tata cara pengelolaan dan pertanggungjawabannya. Eratnya keterkaitan ini mengandung implikasi konsekuensi yuridis, mengingat tata cara pengelolaan dan pertanggungjawaban keuangannya diatur sendiri dan berbeda. Bagi badan hukum publik seperti Negara atau Derah berbeda tata cara pengelolaan dan pertanggungjawaban keuangannya dengan sebuah perseroan terbatas (Persero). ${ }^{10}$

Mahkamah Agung pada Rapat Kerja Nasional Tahun 2010 membedakan keduanya dengan menyebutkan kekayaan negara yang sudah disertakan sebagai modal BUMN atau BUMD yang dapat disita karena kekayaan itu bukan lagi milik Negara melainkan sudah menjadi harta milik BUMN atau BUMD. Namun demikian, apabila uang atau barang milik negara yang bukan penyertaan modal tetapi dikelola oleh BUMN atau BUMD, maka uang atau barang milik negara tersebut tidak dapat dilakukan sita jaminan atau sita eksekusi sesuai dengan ketentuan Pasal 50 Undang-Undang Nomor 1 Tahun 2004 tentang Perbendaharaan Negara (“UU Perbendaharaan Negara”). ${ }^{11}$ Berbeda dengan pernyataan Mahkamah Agung, Mahkamah Konstitusi melalui Putusan Nomor 62/PUU-XI/2013 menyatakan bahwa BUMN/D merupakan kepanjangan tangan Pemerintah dalam menyelenggarakan fungsi pemerintahan dalam arti luas, dengan demikian posisi BUMN/D melakukan pengelolaan keuangan negara, meskipun harus dipahami dengan mempergunakan paradigma bisnis (business judgment rules), yang berbeda dengan paradigma pemerintahan (government judgment rules).

Teori transformasi fungsi dan status hukum uang pada dasarnya merujuk pada teori badan hukum yang sudah dikenal sejak abad ke-19. Hak badan hukum termiliki dalam konsep kepunyaan publik (public domain) dan kepunyaan privat (prive domain). ${ }^{12}$ Transformasi status hukum uang terjadi manakala pemerintah pusat atau Daerah memisahkan kekayaanya menjadi modal dalam suatu perseroan terbatas (Persero) maupun perusahaan umum (Perum). Kekayaan negara atau daerah yang dipisahkan menjadi modal Perseroan Terbatas atau Perusahaan Umum yang dilakukan dengan menggunakan peraturan pemerintah atau keputusan kepala daerah masih dalam lingkungan kuasa

10 Yuli Indrawati, Op. Cit. hlm. 15-16.

11 Isis Ikhwansyah, An-an Chandrawulan, Prita Amalia. (2018). Optimalisasi Peran Badan Usaha Milik Negara (BUMN) pada Era Masyarakat Ekonomi ASEAN (MEA). Jurnal Media Hukum. 25 (2). hlm. 156.

12 Yuli Indrawati, Op. Cit, hlm. 66. 
hukum publik. Akan tetapi pada saat negara atau daerah mendirikan Perseroan Terbatas atau perusahaan umum, negara atau daerah pada saat itu tidak lagi berstatus subyek hukum publik, akan tetapi ia bertindak dalam lingkungan kuasa hukum privat, dan terhadap negara atau daerah sepenuhnya berlaku dan tunduk pada ketentuan hukum perdata. ${ }^{13}$

Pasal 19 ayat (1) PP BUMD mengatur sumber modal BUMD terdiri atas: penyertaan modal Daerah; pinjaman; hibah; dan sumber modal lainnya, meliputi kapitalisasi cadangan, keuntungan revaluasi aset, dan agio saham. Modal saham para pemegang saham BUMD Perseroda tidak hanya terdiri dari kekayaan daerah yang dipisahkan dari Pemerintah Daerah, melainkan juga percampuran dengan modal para pemegang saham lainnya nonpemerintah daerah, sehingga dalam hal ini berlaku teori transformasi status hukum uang yaitu pada saat daerah mendirikan Perseroan Terbatas atau perusahaan umum, daerah pada saat itu tidak lagi berstatus subyek hukum publik, akan tetapi ia bertindak dalam lingkungan kuasa hukum privat, dan terhadap negara atau daerah sepenuhnya berlaku dan tunduk pada ketentuan hukum perdata. Teori ini diperkuat dengan prinsip pemisahan kekayaan pada Perseroan Terbatas (limited liability), yang dianut Pasal 3 ayat (1) UU Perseroan Terbatas yang berbunyi:

"Pemegang saham Perseroan tidak bertanggungjawab secara pribadi atas perikatan yang dibuat atas nama Perseroan dan tidak bertanggungjawab atas kerugian Perseroan melebihi saham yang dimilikinya."

Selanjutnya penjelasan Pasal 3 ayat (1) tersebut mengatakan ketentuan ini mempertegas ciri Perseroan bahwa pemegang saham hanya bertanggungjawab sebesar setoran atas seluruh saham yang dimilikinya dan tidak meliputi harta kekayaan pribadinya. Selaras dengan ketentuan ini, prinsip pemisahan kekayaan BUMD dari kekayaan daerah juga dianut dalam PP BUMD yang baru diterbitkan. Pasal 20 PP BUMD berbunyi:

"Modal BUMD yang bersumber dari penyertaan modal Daerah merupakan batas pertanggungjawaban Daerah atas kerugian BUMD."

${ }^{13} \mathrm{Ibid}$, hlm. 18. 
Ketentuan Pasal 20 PP BUMD ini menegaskan adanya perbedaan arti dan status hukum uang Daerah (publik) dengan arti dan status yuridis uang BUMD (privat) sebagai akibat adanya transformasi fungsi dan status hukum uang, bahwa apabila terjadi kerugian keuangan BUMD tidak mengakibatkan terjadi kerugian keuangan daerah, tetapi yang terjadi adalah kerugian BUMD Perseroda sebagai badan hukum itu sendiri. Negara/daerah sebagai badan hukum publik seharusnya tidak menanggung resiko apapun dalam hal BUMD mengalami risiko. Apabila BUMD mengalami kerugian dan dinyatakan pailit, status pailit tersebut tidak akan menyebabkan badan hukum daerah jatuh pailit atau ikut dipailitkan, Hal ini merupakan bukti konkrit dengan dipisahkannya kekayaan daerah pada BUMD Perseroda, terpisahlah hubungan hukum keuangan BUMD Perseroda itu dengan keuangan daerah sebagai badan hukum publik. ${ }^{14}$ Dengan demikian terpisahnya kekayaan Daerah dan kekayaan BUMD Perseroda menegaskan status kepemilikan aset BUMD Perseroda yang tidak dapat dipersamakan dengan aset/Barang Milik Daerah, bahwa aset BUMD Perseroda adalah kekayaan BUMD yang diperoleh dari sumber pendapatan perusahaan yang diatur dalam Pasal 19 ayat (1) PP BUMD.

\section{Penjaminan Aset BUMD Perseroda dalam Rangka Memperoleh Pinjaman Bank}

Aset adalah barang yang dalam pengertian hukum disebut benda, yang terdiri dari benda tidak bergerak dan benda bergerak. Barang yang dimaksud meliputi barang tidak bergerak (tanah dan/atau bangunan) dan barang bergerak, baik yang berwujud (tangible) maupun yang tidak berwujud (intangible), yang mencakup dalam aktiva/kekayaan atau harta kekayaan dari suatu perusahaan. UU Perseroan Terbatas tidak menggunakan terminologi “aset Perseroan", namun yang digunakan adalah "kekayaan perseroan" sebagaimana diuraikan dalam penjelasan Pasal 102 ayat (1) UU Perseroan Terbatas, yang dimaksud dengan "kekayaan Perseroan" adalah semua barang, baik bergerak maupun tidak bergerak, baik berwujud maupun tidak berwujud" milik Perseroan. Berbeda dengan aset/Barang Milik Daerah, Barang Milik Daerah didefinisikan sebagai: “semua barang yang

\footnotetext{
14 Yuli Indrawati, Op. Cit. hlm. 42-43.
} 
dibeli atau diperoleh atas beban APBN/APBD atau berasal dari perolehan lainnya yang sah". $^{\prime \prime}$

Berdasarkan Pasal 49 ayat (1) UU Perbendaharaan Negara, aset daerah atau barang milik daerah dilarang untuk digadaikan atau dijadikan jaminan untuk mendapatkan pinjaman. Sementara itu, perbuatan hukum menjaminkan kekayaan PT diatur dalam Pasal 102 UU Perseroan Terbatas, bahwa penjaminan kekayaan PT yang merupakan lebih dari 50\% jumlah kekayaan bersih Perseroan dalam 1 (satu) transaksi atau lebih, yang dilaksanakan Direksi harus mendapat persetujuan RUPS, dengan ketentuan kuorum paling sedikit $3 / 4$ hak suara.

Pada BUMD diatur pada Pasal 332 ayat (1) UU PEMDA bahwa pinjaman menjadi salah satu sumber modal BUMD, selain daripada penyertaan modal daerah, hibah, dan sumber modal lainnya. Pinjaman dimaksud dapat berasal dari daerah, BUMD lain, atau sumber lainnya, diantaranya lembaga keuangan bank atau non-bank. ${ }^{15}$ Selanjutnya Pasal 95 ayat (1) dan (2) PP BUMD mengatur dalam konteks pengembangan usaha dan investasi, Pinjaman dapat dilakukan BUMD kepada lembaga keuangan, pemerintah, dan sumber dana lainnya dalam negeri dan dalam hal pinjaman dimaksud mempersyaratkan jaminan, maka aset BUMD yang berasal dari hasil usaha BUMD dapat dijadikan jaminan untuk mendapatkan pinjaman.

Ketentuan Pasal 95 ayat (2) PP BUMD memberikan implikasi bahwa penjaminan aset BUMD dalam rangka pinjaman untuk pengembangan usaha dan investasi dapat dilakukan setelah BUMD memiliki hasil usaha. Ketentuan ini juga memisahkan perlakuan terhadap aset BUMD yang berasal dari hasil usaha ataupun pendapatan BUMD lainya. Pada praktiknya, BUMD berbentuk Perseroda menjaminkan asetnya dalam rangka memperoleh kredit bank meski belum memiliki hasil usaha. Kredit bank tersebut diperlukan untuk operasional perusahaan, seperti pada PT Bandarudara Internasional Jawa Barat untuk keperluan pembangunan bandara dan PT Tirta Gemah Ripah untuk pembangunan dan investasi Pembangkit Listrik Tenaga Air (Minihidro). Aset yang dijaminkan BUMD berbentuk Perseroda tersebut tidak berasal dari hasil usaha, dikarenakan BUMD tersebut

15 Pasal 19 ayat (3) PP BUMD 
masih membukukan rugi, melainkan dari penyertaan modal daerah maupun aset yang dibeli dari hasil pinjaman bank itu sendiri.

PP BUMD tidak mengatur secara eksplisit mengenai penjaminan aset BUMD, terutama apabila aset tersebut tidak berasal dari hasil usaha (kondisi BUMD masih membukukan rugi), namun demikian Pasal 3 ayat (4) PP BUMD merinci kewenangan pengambilan keputusan Kepala Daerah selaku pemegang saham di BUMD yang dapat dilimpahkan kepada pejabat perangkat daerah, salah satunya mengenai jaminan aset berjumlah lebih dari 50\% dari jumlah kekayaan bersih BUMD dalam 1 transaksi atau lebih. Adanya ketentuan ini kemudian menyimpulkan temuan yaitu:

a. PP BUMD secara implisit mengakui bahwa aset BUMD berbeda dengan aset daerah, dikarenakan aset daerah secara tegas dilarang untuk dijaminkan, sedangkan aset BUMD dapat dijaminkan selama aset yang dijaminkan yang berjumlah lebih dari $50 \%$ jumlah kekayaan bersih BUMD harus mendapat keputusan/persetujuan Kepala Daerah (atau pejabatnya yang mendapat pelimpahan wewenang) selaku pemegang saham pada BUMD;

b. PP BUMD secara eskplisit selaras dengan ketentuan Pasal 102 UU Perseroan Terbatas bahwa penjaminan aset PT yang berjumlah lebih dari 50\% dari jumlah kekayaan bersih PT dalam 1 transaksi atau lebih maka Direksi wajib meminta persetujuan RUPS. Penilaian lebih dari 50\% kekayaan bersih didasarkan pada nilai buku sesuai neraca yang terakhir disahkan RUPS.16

\section{KESIMPULAN}

Ketentuan Pasal 20 PP BUMD mengimplikasikan adanya perbedaan arti dan status hukum uang Daerah (publik) dengan arti dan status yuridis uang BUMD (privat) sebagai akibat adanya transformasi fungsi dan status hukum uang. Hal ini merupakan bukti konkrit dengan dipisahkannya kekayaan daerah pada BUMD Perseroda, maka terpisahlah hubungan hukum keuangan BUMD Perseroda itu dengan keuangan daerah sebagai badan hukum publik, sehingga menegaskan status kepemilikan aset BUMD Perseroda yang tidak

\footnotetext{
16 Penjelasan Pasal 102 ayat (1) UU Perseroan Terbatas
} 
dapat dipersamakan dengan aset/Barang Milik Daerah. Dalam rangka penjaminan aset BUMD kepada Bank, meski PP BUMD tidak mengatur secara eksplisit mengenai penjaminan aset BUMD apabila aset tersebut diperoleh dari diluar hasil usaha (misal: penyertaan modal daerah/pinjaman bank) karena kondisi BUMD yang masih membukukan rugi, namun demikian Pasal 3 ayat (4) PP BUMD mengimplikasikan bahwa aset BUMD tetap dapat dijaminkan, meski BUMD tersebut belum memiliki hasil usaha, sekaligus menegaskan bahwa perbedaannya dengan aset daerah karena dapat dijaminkan kepada pihak ketiga serta tidak membeda-bedakan aset mana saja yang dapat dijaminkan.

\section{UCAPAN TERIMA KASIH}

Pada kesempatan ini, penulis bermaksud mengucapkan terimakasih kepada suami tercinta Luke Rimba Gisang, dan orangtua penulis, Bismarck Guruminda dan Sience Abdul Rauf, yang senantiasa memberikan motivasi untuk selalu menjadi yang terbaik. Penulis juga menghaturkan terimakasih kepada Dr. Hj. R. Kartikasari, S.H., M.H. dan Dr. Zainal Muttaqin, S.H., M.H selaku dosen pembimbing thesis yang telah banyak meluangkan waktu, tenaga dan pikiran dalam memberikan bimbingan, masukan dan arahan kepada Penulis.

\section{DAFTAR PUSTAKA}

\section{Buku}

Soerjono Soekanto. (1986). Pengantar Penelitian Hukum. Jakarta: UI Press.

Sumadi Suryabrata. (2010). Metodologi Penelitian. Jakarta: Rajawali Pers.

Tuti Rastuti. (2015). Seluk Beluk Perusahaan dan Hukum Perusahaan. Jakarta: PT Refika Aditama.

Yuli Indrawati. (2014). In Memoriam Prof. Dr. Arifin P. Soeriaatmadja: Aktualisasi Hukum Keuangan Publik, Bandung: Mujahid Press. 


\section{Jurnal}

Sentosa Sembiring (2007). Arti Penting Jaminan dalam Pemberian Kredit dalam Transaksi Bisnis Perbankan. Gloria Juris, 7 (1).

Isis Ikhwansyah, An-an Chandrawulan, Prita Amalia. (2018). Optimalisasi Peran Badan Usaha Milik Negara (BUMN) pada Era Masyarakat Ekonomi ASEAN (MEA). Jurnal Media Hukum. 25 (2).

\section{Peraturan Perundang-Undangan}

Undang-Undang Nomor 1 Tahun 2004 tentang Perbendaharaan Negara.

Undang-Undang Nomor 40 Tahun 2007 Tentang Perseroan Terbatas.

Undang-Undang Nomor 23 Tahun 2014 Tentang Pemerintahan Daerah.

Peraturan Pemerintah Nomor 54 Tahun 2017 tentang Badan Usaha Milik Daerah.

Peraturan Pemerintah Nomor 12 Tahun 2019 tentang Pengelolaan Keuangan Daerah. 